\title{
Aproximaciones a la violencia socio-política, memoria e identidad: Un estudio de caso en el municipio de Arjona- Bolívar
}

\begin{abstract}
Estefany Paola Acuña Reyes, Jasmar Jesús Pájaro Martínez², Jesús Andrés Acuña Reyes ${ }^{3}$

¿Qué claridades, qué entenderes, qué riquezas habrían significado sus vidas en el acumulado de la humanidad en el legado amasado por todos? ¿Qué hombres, qué mujeres perdimos? ¿En qué Ciudades habitarían hoy? ¿Qué hijos tendrían? ¿Qué amores nunca se realizaron? ¿Quiénes serían hoy nuestros amigos? ¿Quién nos explica? ¿Quién nos devuelve el canto rasgado en tan insondable silencio?
\end{abstract}

Gioconda Belli -Un mundo sin Hitler

\section{Resumen}

Si bien Arjona no vivió de forma directa el desplazamiento forzado y masacres, sí vivió diferentes hechos víctimizantes y se constituyó en un referente de refugio para diferentes familias provenientes principalmente de la región caribe con un registro de 6.640 víctimas de acuerdo con la Red Nacional de Información (RNI, 2016). Bajo este panorama y teniendo en cuenta el impacto de la violencia sobre la salud mental (OPS, 2002), la política de reparación y atención a las víctimas, la Universidad Metropolitana en apoyo con la Fundación Instituto de Educación e Investigación -FUIMZO- desarrolla un proyecto de investigación que tiene como objetivo reconstruir la memoria histórica de la población víctima de violencia socio-política ubicado en Arjona-Bolívar, sus corregimientos y veredas, mediante procesos de inclusión

\footnotetext{
1 Magíster en Desarrollo Social, Universidad del Norte (Colombia). CMaster en Sciences de la Societé, Universidad Paris-Est Créteil Val de Marne (Francia). Psicóloga, Universidad del Norte (Colombia). Docente e investigadora Universidad Metropolitana (Barranquilla- Colombia). Correo electrónico: eacuna@unimetro.edu.co.

2 Historiador Universidad de Cartagena. (C) Master en Conflicto Social y construcción de paz, Universidad de Cartagena. Miembro del Grupo de investigación Frantz Fanon. Línea de investigación Formas Organizativas, Movimientos Sociales y Participación, del Instituto de Educación e Investigación Manuel Zapata Olivella (FUIMZO). Correo electrónico: jasmarpajaro@gmail.com

3 Profesional en Relaciones Internacionales con énfasis en Economía Internacional, Universidad del Norte (Colombia). Trade Marketing Advisor. Línea de investigación Estudios Regionales y Política Exterior Comparada e Identidad(es). Correo electrónico: jacunaa@uninorte.edu.co
} 
de la voz, re-significación de la vivencia, identificación de acciones de paz, establecimiento de las características del daño individual y colectivo sufrido, y sus efectos consecuencias, des de el marco de la Investigación acción participativa (IAP). Para efectos de este capítulo se presentará un estudio de caso único que tenía por objetivo comprender la re-construcción de la historia personal a partir de la vivencia-co-investigadora- de la víctima. Resulta imperativo señalar dentro de los resultados que si bien se encuentra presente una desesperanza respecto a la percepción que se tiene de las situaciones cotidianas, del día a día y su afrontamiento y sin dejar de reconocer el trauma ocasionado por la violencia, en el estudio de caso, se da cuenta de elementos de bienestar y recursos, donde los hijos y nietos se convierten en el motor principal para salir adelante y afrontar las diferentes situaciones diarias.

Palabras clave: memoria, violencia sociopolítica, salud mental, trauma psicosocial e identidad.

\section{INTRODUCCIÓN}

El municipio de Arjona (Bolívar-Colombia) cuenta aproximadamente con un $4 \%$ de su población total identificada como víctimas del conflicto. Y debido a sus condiciones geográficas, sociales y culturales existentes, se presenta una Leit motiv, para la atracción y el asentamiento de personas nacidas en otros espacios y que se reconocen como víctimas, lo que hace impostergable la realización de análisis focalizados y contextualizados de esta población; sumado a la construcción de interpretaciones de los movimientos de los flujos poblacionales que incluso se dan desde Arjona hacia otros países, lo que evidencia que además de la población referenciada, el municipio mantiene una población flotante que hace que sus condiciones demográficas sean más o menos variables y sus dinámicas sociales complejas.

Si bien el Municipio de Arjona no vivió de forma masiva y directa hechos como el desplazamiento forzado y masacres, su población si vivió otras manifestaciones de violencia, violación de los derechos humanos y delitos considerados de lesa humanidad, dentro de los que se encuentran diferentes hechos victimizantes como el hostigamiento, amenazas, desapariciones forzadas, homicidios y secuestros, entre otros. De esta manera la incursión de grupos armados en el territorio, obedeció a una táctica distinta de hacer la violencia; esto quizás por razones geográficas y culturales. Así el actuar violento se centró en la intimidación con panfletos, entre otros medios, y las muertes selectivas derivadas también de lo anterior, lo que llevo a que el sufrimiento y el dolor en los pobladores fuera de una manera particular a otras zonas del departamento de Bolívar. 
Bajo estos presupuestos, el municipio de Arjona se constituyó en un referente de refugio para personas y familias provenientes de diferentes regiones de Colombia víctimas principalmente de desplazamiento, despojo forzado de sus tierras y/o por amenazas. Tanto así que la primera encuesta nacional de víctimas de la Contraloría General de la República en el año 2013, revelo que el municipio hace parte de los once (11) centros urbanos más importantes de recepción de víctimas de desplazamiento a nivel nacional, siendo Bogotá y su área metropolitana el principal receptor. En esta misma línea y de acuerdo con el Registro Único de Victimas en su reporte con corte del primero (01) de diciembre de 2015, el Municipio cuenta con un total de 2.008 personas en condición de desplazamiento forzado.

Asimismo, este Municipio portador de una cultura de paz y armonía entre los hombres y la naturaleza que desde sus orígenes históricos sostiene las relaciones sociales, económicas, territoriales, ambientales y artísticas, que lo ha diferenciado de forma positiva en la región Caribe; fue afectado violentamente desde hace décadas cuando se dispara el espiral de violencia que inaugura uno de los periodos más tristes de la historia de Colombia, al producirse el desplazamiento de millones de personas por razones políticas, económicas, culturales, territoriales y ambientales, entre los que un alto porcentaje responden a la condición étnica y otras de carácter diferencial.

El impacto de los hechos referenciados fue de enorme valía desde el punto de vista socio-económico, territorial, cultural y psicológico en la medida que las personas tuvieron que abandonar sus tierras tradicionales y en particular la agricultura como principal actividad económica, quedando atrás los grandes momentos de producción de "yuca, ñame, plátano, maíz, arroz", entre algunos otros productos dignos de mencionar, incrustados en la existencia histórica de la población y soportados por la convivencia tranquila, la espiritualidad y el afecto presente en su labor cotidiana.

Es así como inicia un nuevo periodo en la vida del pueblo y se gestan esfuerzos enormes en el sentido de buscar restablecer la dignidad, iniciándose un proceso de recuperación y reconstrucción de la memoria histórica como soporte identitario de los derechos, desde el punto de vista territorial, económico, social, cultural, ambiental y sobre todo de la gran memoria construida en el espacio y tiempo de la existencia.

En el contexto de la problemática que afecta a la población víctima en el departamento de Bolívar, se inicia un proceso social y organizativo para avanzar en la reparación de los daños causados y devolver la dignidad 
estropeada y vilipendiada por los actores más representativos del conflicto. Estos esfuerzos son de índole legal en el marco de los derechos que tiene la población desplazada y población vulnerable, pero también son de naturaleza territorial en su expresión del retorno al territorio tradicional mediado por la existencia de condiciones socioeconómicas apropiadas y de naturaleza psicológica e identitaria en su manifestación de reconstrucción de los hilos de la memoria colectiva como sujetos históricos de derecho.

En fin, estos esfuerzos están dirigidos a la conservación de una vida digna para un conglomerado social que lo único que ha hecho en sus siglos de existencia es reproducir la armonía con la naturaleza y la sociedad en general. Con el propósito de que las nuevas generaciones de colombianos y personas en el mundo, conozcan lo sucedido, aprendan la lección y experiencia vivida, los principales líderes de la población narran lo vivido, cuentan lo aprendido y aconsejan seguir los ejemplos de tesón y resiliencia para impedir que lo ocurrido, vuelva a repetirse en la historia de algún pueblo.

Cabe resaltar que en el marco complejo de las víctimas y teniendo en cuenta lo propuesto por Gaborit (2012) que, en los conflictos armados, la identidad personal y colectiva se convierte en los principales "objetivos de guerra" y que esta destrucción no se da por casualidad ni como efecto secundario, sino que es una meta que aún permanece después de finalizado el conflicto bélico, asegurando que la narrativa de las víctimas quede en el olvido o en la sospecha.

En ese sentido desde este proyecto de investigación liderado por la Universidad Metropolitana pretende por un lado a la idea de mantener viva la memoria del Municipio de Arjona, como fuente de identidad, valor ético, democrático, y de paz, que orienten el diseño de estrategias de intervención psicosocial y los procesos de reparación y cumplimiento de los derechos como colectividad y comunidad afectada por los diferentes hechos victimizantes; y por otro lado desde un punto de vista cimero se aporta a la definición de los lineamientos para la reparación simbólica de las víctimas y a la protección de los derechos de verdad, justicia, reparación y no repetición contemplados en la ley.

\section{CONTEXTUALIZACIÓN DEL PROBLEMA}

Arjona es un municipio que se encuentra ubicado geográficamente en el norte del departamento de Bolívar-Colombia y cuenta con cuatro corregimientos que son los poblados de Rocha, Puerto Badel, Sincerín y Gambote, cada uno de ellos ubicado a las orillas del canal del Dique. La extensión del municipio es de $566 \mathrm{Km}^{2}$, posee una altura a de 63 (msnm), 
mantiene una temperatura promedio de $28{ }^{\circ} \mathrm{C}$, y su territorio es totalmente ondulado con algunas elevaciones que no pasan de los 200 (msnm). Según sus delimitaciones geográficas, se encuentra al norte con el municipio de Turbaco, al este con los municipios de Mahates y San Estanislao, al sur con María La Baja, al oeste con Turbana y al sureste con el municipio de San Onofre (departamento de Sucre) con quien comparte una importante reserva natural y santuario de flora y fauna denominado El Corchal "El mono Hernández".

Así, al reconstruir la memoria histórica del municipio de Arjona, de sus corregimientos y veredas, mediante procesos de participación activa, y sobre todo del reconocimiento a la voz y las memorias de las víctimas y su contextualización en la realidad del conflicto armado, no es una simple responsabilidad hacia la aplicación de la ley de víctimas y restitución de tierras (1448 de 2011) y la ley de justicia y paz (ley 975 de 2005), es un deber que debe integrar no solo organismos institucionales, sino los esfuerzos de todos los pobladores que hayan o no, vivido en forma directa los horrores de la violencia.

Quienes padecieron el flagelo del desplazamiento forzado y los otros hechos violentos antes señalados, lo hicieron especialmente por vicisitudes generadas a partir de causas que esencialmente tienen que ver con disputas territoriales entre grupos armados al margen de la Ley en otras zonas del departamento de Bolívar, que para el caso concreto de las comunidades en mención; los distintos grupos armados acusaban a sus pobladores de ser auxiliadores de uno u otro bando guerrillero o paramilitar, presentes en ese momento en el territorio. Bajo este pretexto cometieron un sin número de asesinatos selectivos con el fin de acabar con el supuesto apoyo que la población civil les brindara a los grupos insurgentes, estatales y/o paraestatales. Otro modus operandi del conflicto era la justificación práctica de una limpieza social, enfocada sobre todo en el fortalecimiento del control social y territorial. En este contexto, por ejemplo, las Autodefensas Unidas de Colombia (AUC) llegan a estas comunidades generando terror dentro de la población, bajo el surgimiento de múltiples casos de intimidaciones, amenazas, todo en un marco de formas tácticas y estratégicas de guerra. Así, desde lo propuesto por Martín-Baró (2003) la violencia socio-política se convierte en la expresión de un conflicto que usa el dolor y el sufrimiento para homogenizar y controlar la conducta de las personas, sembrando miedo, incertidumbres y desesperanza. 
Las muertes selectivas, y la recepción de familias completas y fragmentadas que huían de la violencia, ocasionaron un cúmulo de problemas contra la población civil generando impactos como la desarticulación del tejido socio-cultural, perdida del arraigo a la tierra, lo anterior, sobre todo teniendo en cuenta que las comunidades víctimas tenían ligadas sus vidas, al desarrollo de actividades principalmente agropecuarias, lo que originó que los imaginarios culturales se deterioraron en los cascos urbanos receptores, generando que los pobladores pasaran a engrosar los cinturones de miseria de los pueblos y ciudades.

Por lo anterior, se hace necesario reconstruir las memorias del Municipio en mención con el firme propósito de recuperar los elementos culturales propios, debido a que gran parte de las familias desplazadas a pesar de las condiciones de desamparo, mantienen su identidad cultural, y por principium individuationis, requieren del esclarecimiento de la verdad de los hechos, y la recuperación de su voluntad histórica, que les permita desarrollar la vida social, cultural, política y económica, revalidando el sentido de pertenencia a la tierra natal. Resaltando que el desplazamiento forzado y demás hechos victimizantes, trajo consigo la estigmatización de las personas como pertenecientes a grupos armados ilegales, y, en consecuencia, la recuperación de la memoria histórica aportará matices esenciales de la vida anímica desde la óptica comunitaria, y de la lógica del conflicto, que desmitificará la marginalización que les aplicaron como supuestos miembros de grupos armados, entre otros.

\section{El proceso de re-construcción como un llamado: Memoria e identidad}

El proceso de reconstrucción de la memoria histórica de las victimas del Municipio de Arjona-Bolívar implica un análisis de contexto no solo sobre las implicaciones, sino también sobre las consecuencias del conflicto armado que desde hace décadas afecta a Colombia, y que hicieron del municipio de Arjona.

Así, estos resultados presentados en este capítulo se constituye en un documento, que pretende ser una aproximación a la reconstrucción de la historia personal a partir de la vivencia, porque más que entender y razonar sobre la población, la naturaleza misma de los hechos, no se puede reconstruir, si es que es posible hacerlo de manera abstracta, sino se siguen las señales del Pro gredere, ir adelante, que se manifiesta con las víctimas en cada acto, testimonio y relato como muestra inequívoca de las energías transformadas en fuerzas vitales, que hacen que exista siquiera la posibili- 
dad de querer ir al pasado, y en consecuencia ser artífices A Modu propio de su destino. El llamado es a construir más allá de las historias, relatos y memorias, un discurso acorde al espacio y tiempo que vivimos, y que represente a todos, no solo a las víctimas directas, sino también al pueblo y a las gentes en general, más allá del horizonte visible y de las coordenadas sentidas, para que de verdad se inocule e incite con fervor, la fundación de una nueva vida, bajo el principio rector de, Res non verba, hechos y no palabras, que en ultimas es la forma más viva de echar bases para el futuro.

En este orden de ideas, Beristaín (2000) sostiene que los relatos y testimonios no solo tienen un valor social y colectivo, sino también terapéutico porque permite conocer de forma individual y general la existencia y realidad de los hechos, mantiene el hilo del pasado con el futuro por medio de la narración de los mismo en el presente, promueve un proceso catártico personal y grupal en el que se reintegra la experiencia en la historia vital y mutua que ayuda a ir desalojando el dolor; abre espacios para la dignificación de las personas y las comunidades a partir de la reparación social; reconstruye la identidad; forja escenarios para la expresión en la que se alivian los malestares íntimos, y genera puntos para la reflexión y la no repetición. Así mismo, se convierte en un paso para la verdad, la justicia y la reparación.

\section{Arjona municipio receptor de vidas y testimonios}

En el reporte con fecha primero (01) de noviembre de 2015, emitido por la Unidad de Victimas, ente encargado por la Ley 1448 del 2011 para atender y reparar integralmente a las víctimas del conflicto armado, en el Municipio de Arjona-Bolívar a la fecha, se han recibido 6.547 Declaraciones de Victimas. Lo que lo hace ser uno de los lugares más importantes de acopio de testimonios y de víctimas del conflicto colombiano.

Según la citada ley, la declaración de víctima, es el testimonio sistematizado de la persona que, a nombre propio y de su hogar, manifiesta ser víctima de la violencia. La también denominada Ley de Victimas considera como tal a las personas que individual o colectivamente sufrieron un daño por hechos ocurridos a partir del 01 de enero de 1985, como consecuencia de violaciones graves y manifiestas de las normas internacionales de Derechos Humanos y de infracciones al Derecho Internacional Humanitario, ocurridas con ocasión del conflicto armado interno. Entre los hechos que se señalan y que pueden ocasionar la existencia de víctimas del conflicto, se encuentran: homicidios, masacres, secuestros, desaparición forzada, tortura, delitos contra la libertad y la integridad sexual, minas antiperso- 
nales, munición sin explotar y artefacto explosivo improvisado, vinculación de niños, niñas, y adolescentes a actividades relacionadas con el conflictos, acto terrorista, atentados, combates, enfrentamientos y hostigamientos, abandono forzado o despojo forzado de tierras, o desplazamiento forzado, entre otras. También se consideran víctimas las personas que hayan sufrido un daño al intervenir o asistir a las víctimas de los hechos antes referidos que estuviesen en peligro, o para prevenir una victimización. Así mismo son víctimas los niños que nacieron a causa de un abuso sexual cometido en el marco del conflicto armado.

Los números reportados por la Red Nacional de Información (RNI, 2016), nos permite hacer análisis desagregados y diferenciados del universo poblacional dentro del territorio nacional, permitiendo así una visión más exacta de la realidad y del contexto social que viven las víctimas en el municipio de Arjona y que se puede revelar de forma resumida, indicando que de todas las declaraciones recibidas, el $50 \%$ de la población víctima son hombres, y el $49 \%$ son mujeres. El $29 \%$ de los declarantes son jóvenes entre los 0 y los 18 años, y el 67\% restante, son personas en mayoría de edad, lo que muestra que el conjunto de víctimas, en suma, se encuentran o deberían estarlo, en etapa de formación y/o de producción. Así mismo el reporte indica que el $33 \%$ de esta parte de la población declarante, se auto-reconocen como Afro-descendientes siento este, el grupo poblacional más afectado por la segunda causa de victimización después del desplazamiento, como lo es el homicidio, con un $92 \%$ de los casos declarados.

En lo que respecta a los hechos víctimizantes, se indica en el reporte que el desplazamiento se encuentre en primer lugar con un 93\% de las personas declarantes en el municipio de Arjona con un total de 6079 casos registrados y el homicidio con un 6\% (383 casos) y en su orden los siguientes hechos victimizantes: amenazas, delitos contra la integridad sexual, desaparición forzada, secuestro, perdida de muebles o inmuebles y actos terroristas (Ver tabla 1).

Tabla 1. Casos por hecho victimizante en el Municipio de Arjona.

\begin{tabular}{|c|c|c|}
\hline HECHO VICTIMIZANTE & $\mathrm{N}^{\circ}$ DE CASOS & $\%$ \\
\hline Acto Terrorista & 3 & $0,05 \%$ \\
\hline Amenazas & 31 & $0,47 \%$ \\
\hline $\begin{array}{c}\text { Delitos contra la integridad } \\
\text { sexual }\end{array}$ & 17 & $0,26 \%$ \\
\hline Desaparición forzada & 17 & $0,26 \%$ \\
\hline
\end{tabular}




\begin{tabular}{|c|c|c|}
\hline HECHO VICTIMIZANTE & $\mathrm{N}^{\circ}$ DE CASOS & $\%$ \\
\hline Desplazamiento & 6079 & $93 \%$ \\
\hline Homicidio & 383 & $6 \%$ \\
\hline Perdida de muebles o inmuebles & 6 & $0,09 \%$ \\
\hline Secuestro & 11 & $0,17 \%$ \\
\hline
\end{tabular}

Nota: Elaboración propia, basada en los reportes de información de la Unidad para la atención y reparación integral de víctimas (2016).

Es importante hacer la anotación en el sentido de que la mayoría de las víctimas declarantes, lo son en un $99 \%$ por estar tipificadas por el conflicto armado, y el $1 \%$ restante son víctimas reconocidas por la Corte Constitucional bajo Sentencia judicial C280 y Auto 119 de 2013, que obliga a incluir en la población a reparar, a los afectados por las llamadas bandas criminales emergentes (BACRIM), que surgieron a mediados de 2006, una vez terminado el proceso de desmovilización de las Autodefensas Unidas de Colombia (AUC) bajo los acuerdos con el gobierno nacional de la época, dado que la violencia de esas estructuras armadas se incrementó de forma sustancial.

Bajo estos presupuestos cabe resaltar que un análisis diferencial de las víctimas declarantes permite generar un análisis enfocado a partir de los distintos grupos y categorías sociales nos permite hacer relaciones que llevan a interpretaciones y conclusiones de las disimiles realidades, que no solo ayudan a un mejor entendimiento y a una mayor comprensión de la vida de estas poblaciones sino a llevar a cabo intervenciones sociales más precisas y eficaces.

\section{PRECISIONES METODOLÓGICAS}

Esta primera fase del proyecto se desarrolló de acuerdo con el enfoque de una investigación cualitativa, bajo el diseño de un estudio de caso. En esta misma línea y retomando los postulados teóricos de Eisenhardt (1989) el estudio de caso se define como una propuesta de investigación orientada a comprender las dinámicas presentes en contextos singulares. En el estudio de caso desde lo propuesto por Martínez (2006) se afirma que los datos pueden ser obtenidos desde una variedad de fuentes: documentos, registros, entrevistas, y observaciones. Bajo estos presupuestos se señala la pertinencia del estudio de caso dentro del desarrollo de la presente investigación pues, a partir de una perspectiva holística y experiencial, es posible la acotación intencionada de la ruta del desplazamiento y el impacto que genera la violencia sociopolítica a nivel de salud física y mental a 
partir de una validación intersubjetiva, la rigurosidad y la sistematicidad de los resultados de la investigación.

\section{POBLACIÓN PARTICIPANTE Y PROCEDIMIENTO}

Para la selección del sujeto participante en el estudio de caso, el criterio que se tuvo en cuenta fue que él/la participante fuese víctima de violencia sociopolítica en el marco del conflicto armado en Colombia y actualmente tenga el municipio de Arjona como lugar de residencia.

Los instrumentos y técnicas utilizados para recopilar los datos se implementaron la técnica de relato de vida, la cual se desenvuelve por medio de entrevistas, con una participación mínima del investigador. El entrevistado cuenta una parte especifica de su vida. Los datos recogidos permiten recuperar el testimonio oral ante ciertas experiencias vitales, con el fin de describir la vivencia o experiencia subjetiva de las diferentes dimensiones del tema estudiado (Breilh, 1997). Así mismo la observación participante, a partir del desarrollo de diarios de campo para el registro y sistematización de las observaciones realizadas.

\section{Procedimiento}

Para efectos metodológicos se especifican varias etapas dentro del procedimiento de investigación, sin embargo es necesario resaltar que durante todo el desarrollo de la investigación se llevó a un proceso de intercambio permanente de validación, mediante un proceso cíclico de recolección-análisis y devolución de la información obtenida, de manera que la retroalimentación dada por la participante permitiera obtener la validez intersubjetiva e ir construyendo el conocimiento desde y con el mismo sujeto de investigación.

A continuación, se describen las etapas del proceso desarrollado:

Etapa I: Selección del caso de estudio, mediante un muestreo no probabilístico de caso típico, se tuvieron en cuenta los siguientes criterios para la selección del caso de estudio de la investigación:

a) Ser víctima de violencia sociopolítica en el marco del conflicto armado en Colombia

b) Residente del municipio de Arjona- Bolívar

Etapa II: Aplicación, sistematización y análisis de las entrevistas semi-estructurada, mediante un análisis de contenido cualitativo de tipo inductivo en el que las categorías de análisis fueron definidas a partir de una lógica emergente rastreada en el discurso del caso de estudio. Así mismo la sistematización, identificación y categorización de datos recurrentes y 
relevantes de la observación

Etapa III: Análisis, integración y validación del análisis de resultados con el caso de estudio -Validez intersubjetiva-

\section{RESULTADOS}

Para el análisis de estos datos cualitativos se realizó un análisis de contenido de tipo inductivo de las entrevistas semi-estructuradas desarrolladas para el caso de estudio, implementando el Software para análisis cualitativo Atlas Ti, versión 6.0. Para este proceso se definieron supra-categorías, categorías y subcategorías de análisis las cuales se detallan a continuación (Gráfica 1).

\section{Vivencias personales y familiares de la violencia sociopolítica}

Esta supra-categoría de análisis hace referencia a las vivencias de la participante y su familia, antes del desplazamiento, durante el afrontamiento de los diferentes hechos victimizantes y el impacto y consecuencias del mismo sobre sus vidas.

\section{Contextualización: antes del momento del desplazamiento}

Antes del desplazamiento la participante vivía en Montería, allí vivía con sus padres, abuelos, su hijo mayor -2 años de edad-, trece hermanos, tíos y primos en una finca con una casa amplia en la que habitaban toda su familia, allí tenían sus cultivos y crías de animales especialmente de terneros y chivos. Dentro de los principales recuerdos de la infancia, relata uno asociado a las "salidas al monte" en las que compartía con su familia, especialmente con sus hermanos y primos, este recuerdo se hace vivo en la siguiente expresión de la participante [...] lindo, todo, nos íbamos todos, mis primos, mis hermanos, nos montábamos en esos caballos e íbamos a chorro [...] y otros momentos asociados a las labores de la finca cuando ayudaba en la cocina con su abuela. Así mismo recuerda que a los trece años sale de su casa a buscar trabajo en Cartagena y luego regresa a la finca [para esa época recuerda que tenía 20 años]. Por eso resalta que durante su estancia en Cartagena ella "ya conocía para acá [Arjona] y al momento de desplazarse tomo el mismo camino".

\section{La violencia en el pueblo y la ruta del desplazamiento}

La participante indica que cuando regresa al pueblo ya "las cosas estaban cambiando", la población estaba siendo afectada por la violencia, por el control de los grupos armados y la tierra. De acuerdo con sus expre- 
siones: [...] se metían esos hombres armados a las fincas en la noche [...] y se llevaban y/o mataban los animales de las fincas, esto se hace explícito en su discurso, [...] llegaban aquí y le pedían un ternero una vaca o lo que fuera y si usted decía que no se metían mataban los que podían matar y se los llevaban [...] o [...] dejaban los animales muertos [...]. Se llevaban a los niños y jóvenes del pueblo indicándonos que [...] en el campo, allá es que los reclutaban y se los llevaban. venían y se llevaban a los jovencitos del pueblo [...].

Así mismo recuerda como en ese momento su abuela decidió vender la finca "grande", donde vivían todos [...] mi abuela vendió, mal vendió, nos decía que nos fuéramos y yo me fui donde estaba mi papá [...]. En esta misma línea y retomando el informe del Observatorio del Programa Presidencial de Derechos Humanos y Derecho Internacional Humanitario (2009), y los cambios que manifiesta la participante hace referencia a que la violencia ejercida desde mediados de 60's por las guerrillas liberales era particularmente resultado de conflictos agrarios. Así mismo para esta época 1967-1980 "surgen y toman cuerpo el Ejército Popular de Liberación (EPL) y las Fuerzas Armadas Revolucionarias (FARC) y las primeras expresiones de las autodefensas "las guerrillas de izquierda tuvieron como objetivo la toma del poder por la dinámica de la violencia en el departamento de Córdoba 1967-2008" (p. 84 y 85).

La participante recuerda como el 25 de agosto de 1980, los grupos armados [en su testimonio hace alusión a la incursión de las guerrillas] se llevan a su hermano de 17 años de edad y amenazaron a toda la familia, dándoles 24 horas para salir del pueblo. Recuerda que [...] Para ese año tenía 23 años, estaba yo apenas empezando la barriga del último [...]. Manifiesta en su discurso que salieron todos sus familiares y se aventuraron por una "trocha", recuerda que ella que estando embarazada sale con todos y [...] uno en el brazo lo ponía a caminar por ratico, todos salimos, mis hermanos me ayudaban, salimos por una trocha y acá en la carretera el camión nos recogió y nos dejó en "la Y" y de allí cogimos venia un bus y nos montamos y llegamos, allá cada uno cogió para su lao, mi papi ninguno se quiso venir conmigo, les dije que yo conocía pa allá, y me vine sola con mis pelaitos, sola pa acá [...]. [...] todos se fueron con mi papa yo fui la única que cogí pa acá [...] [...] a pie por trochas, para poder salir a la carretera [...], menciona que no pudieron recuperar nada, al salir tuvieron que dejar todo para salvaguardar la vida, esto se hace explícito en su discurso [...] dejamos todo, dejamos una cría de chivos, marranos, gallinas, toooo too se quedó, todos nosotros lo que traíamos puesto y una bolsita con trapitos cada uno, no 
Aproximaciones a la violencia socio-política, memoria e identidad: Un estudio de caso en el municipio de Arjona- Bolívar

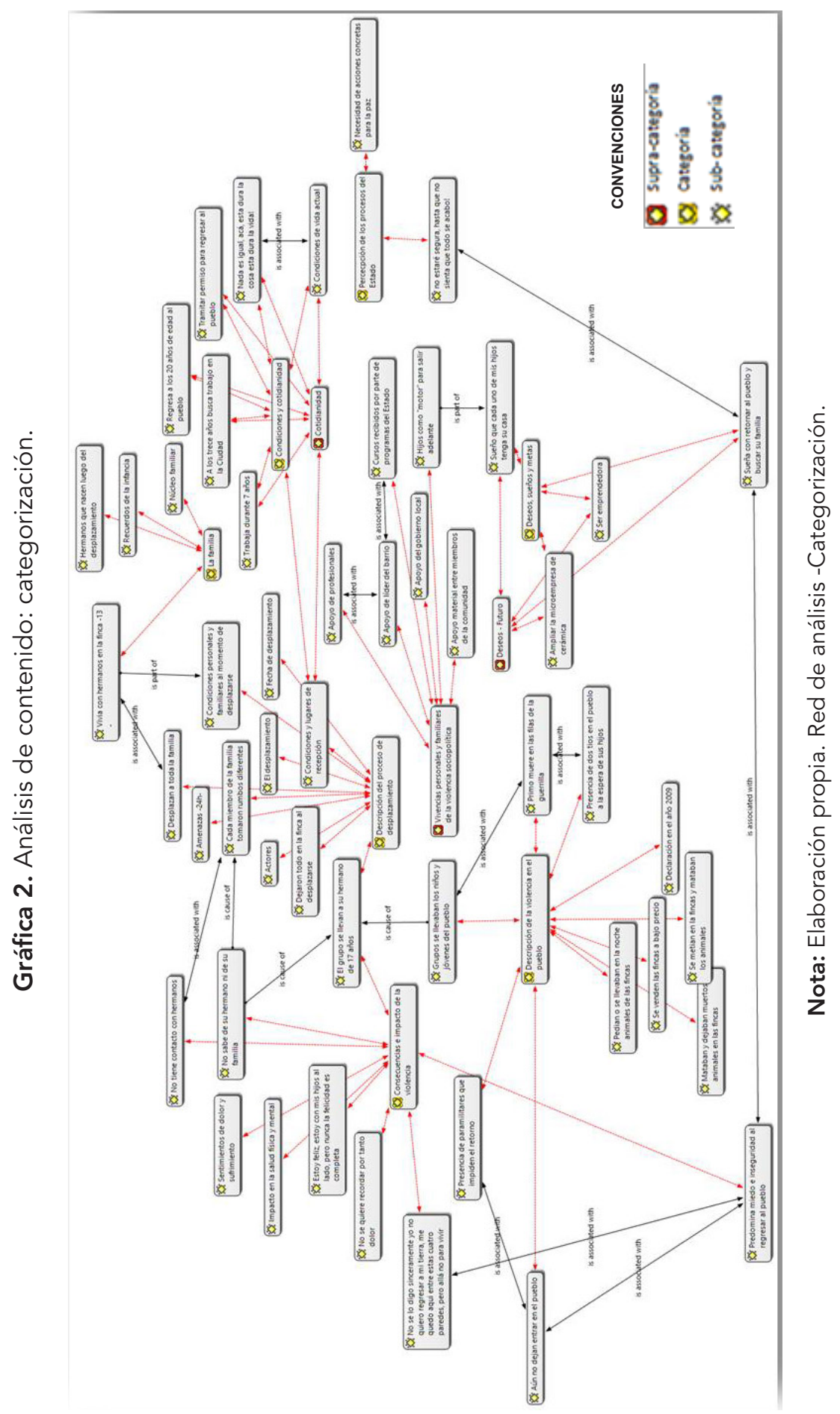


sacamos más nada, todo se quedó [...]. Así, frente a toda esta situación de amenaza, miedo y desespero, la participante y los miembros de su familia, lucharon por preservar sus vidas, saliendo de la finca y dejando todo en el pueblo. Recuerda como dos de sus tíos se quedan en el pueblo porque uno de sus primos, "se fue a las filas de la guerrilla", señala que hace poco lo mataron, pero que la presencia de sus tíos en el pueblo es la única esperanza y oportunidad para encontrar a los demás miembros de su familia, luego de haber salido hace 36 años de su pueblo.

Resulta imperativo en este apartado resaltar que los desplazamientos forzados y demás hechos victimizantes presentados en 1980 en Córdoba presentan un sub-registro o ausencia del mismo respecto al total de víctimas de las diferentes acciones de los grupos armados. De acuerdo con el Observatorio del Programa Presidencial de Derechos Humanos (2009: 75) al hacer un análisis de la violencia de Córdoba, indica que "no se dispone de información sobre desplazamientos de población sino desde 1997. Sin embargo, a partir de la información recolectada en el departamento, se pudo establecer que entre 1985 y 2008, los desplazamientos de población se presentaron de manera ininterrumpida a, aunque con fluctuaciones". En esta misma línea el Registro Único de Víctimas (RUV, 1 de junio 2016) indica un total de 1985 personas expulsadas de sus tierras, 425 personas recibidas y 4 personas declaradas antes de 1985.

\section{Consecuencias e impacto de la violencia}

El terror, el miedo, la desesperación, el dolor y el sufrimiento se convierten en las emociones que priman al analizar el discurso de la participante. Enfrentar la pérdida de sus familiares, la desaparición forzada de su hermano [de quien no tiene información desde la salida del pueblo], la muerte de su primo en la guerrilla y la perdida de contacto con sus padres y el resto de sus hermanos. En medio del silencio, el dolor y la incertidumbre, se pregunta "dónde estará su hermano, si aún se encuentra con vida", de acuerdo con la RUV (1 de junio de 2016) se estima un total de 2.549 personas víctimas de desaparición forzada en el Municipio de Córdoba. Así mismo la participante se pregunta, "si sus padres aún viven, ¿dónde están?", la última información que tiene de ellos, es que se trasladaron a Guadual, Antioquia, pueblo que también fue víctima de desplazamiento en el marco del conflicto armado en Colombia. Esta incertidumbre que acompaña a la participante durante 36 años, sumado a las condiciones de vulnerabilidad al llegar al Municipio de Arjona Bolívar, le llevan a invadir un terreno y luego de "años de lucha" y "lobby político", le hacen entrega de un lote, esto se 
hace explícito en su discurso cuando indica: [...] después de tanto tiempo con él [...] como yo estaba siempre con él me regalo una tierrita y empecé pero luego eso estaba muy lejos y la cosa estaba maluca, vendimos y compramos acá este lotecito, aquí estoy con mis hijos [...]. Así mismo resalta como sumado a un contexto socio-económico de pobreza, se suman las pandillas en el pueblo, manifiesta que en cualquier momento a cualquier hora están robando y no importa nada, que está muy caliente la situación en el barrio donde se encuentra.

Bajo este panorama y retomando las propuestas teóricas de Negrete (1994); Ramos Ramos, Pratts, González, Bernal, Jiménez, Flores y González (2004), el desplazamiento forzado no solo hace alusión a la situación vivida de manera involuntaria y colectiva, sino que incluye también la situación violenta que lo precede, el destierro y el esfuerzo por reestructurar su vida después de ocurrido el suceso en lugares ajenos -lugares receptores-, con indudables desventajas económicas, sociales, culturales y políticas.

De esta manera los diferentes hechos victimizantes en el marco del conflicto armado, sumado a los estresores diarios no solo afectan y tienen consecuencias directas en la salud física, sino que también tiene un impacto negativo en la salud mental no solo de la participante sino de los demás miembros de su familia. De manera particular se podría inferir en el caso de la participante, la presencia de signos de estrés postraumático a causa del trauma ocasionado por la violencia, manifestado de acuerdo con el discurso de la participante en sueños de carácter recurrente sobre el acontecimiento vivido causándole malestar e hipervigilancia, asociación de eventos cotidianos con recuerdos traumáticos del pasado y el esfuerzo constante por evitar pensamientos, sentimientos o conversaciones sobre el suceso traumático. De acuerdo con lo propuesto por Martín-Baró (1988) El trauma "deja secuelas negativas [...] se trata de una herida, es decir, de una huella desfavorable para la vida de la persona" (p. 77).

Desde esta propuesta teórica y retomando el Manual Diagnostico y Estadístico de los Trastornos Mentales (DSM IV-TR), el trastorno de estrés postraumático es:

Un síndrome o patrón comportamental o psicológico de significación clínica, que aparece cuando una persona ha sufrido o ha sido testigo de una agresión física o una amenaza para la vida de uno mismo o de otra persona y cuándo la reacción emocional experimentada e implica una respuesta intensa de miedo, horror o indefensión (American Psychiatric Association, 1994 citado en Echeburúa, Corral, Amor, Zubizarreta y Sarasua, 1997). 
Bajo este panorama Al considerar como este terror impartido en situaciones de violencia y las consecuencias psicosociales que genera la experiencia del desplazamiento tanto en la salud mental como en el desarrollo personal y familiar de las personas que han sido víctimas de este flagelo, se está reconociendo las condiciones que producen el trauma, lo sitúan en la vida de las personas y lo prolongan indefinidamente. Desde la propuesta de Marín-Baró (1988) se señala la necesidad de:

[...] mirar no sólo al sujeto que lo sufre, sino a la situación que lo alimenta, al contexto que le da cobertura, a la estructura que lo origina, lo institucionaliza y lo mantiene. No se trata solo de mirar "fuera" del sujeto, sino de mirar "antes" de que ocurra el trauma, prestar atención a la situación pretraumática, porque es en ella donde se encuentran algunas de las clave del daño psicológico que arrastra, y todas las claves del desorden social que acarrea [...] (Blanco \& Díaz, 2004: 241).

Resulta imperativo señalar en este punto, retomando los postulados teóricos presentados anteriormente, que el impacto de la violencia no afecta a todas las personas de la misma manera y no va a generar los mismos efectos y consecuencias sobre su salud. Lo anteriormente expuesto se hace evidente en el discurso de la participante al indicar [...] se lo digo sinceramente yo no quiero regresar a mi tierra es recordar, fue muy doloroso, prefiero quedarme en estas cuatro paredes [...].

\section{Cotidianidad}

La participante manifiesta que "las cosas ya no son iguales", haciendo referencia a su discurso de la situación económica que ha enfrentado junto a sus hijos en el Municipio, expresa que al llegar fue necesario buscar un refugio, trabajar y luchar por sobrevivir en un nuevo lugar, al respecto señala [...] nada es igual, esta dura la cosa, están muy caras las cosas, esta dura la vida [...]. Un aspecto evidente en el discurso y que se vincula de manera indisociable a lo anteriormente expuesto, es la "añoranza" de la vida que tenía en la finca y en el pueblo al momento de reconstruir su pasado y evaluar su vida, resalta que se siente más tranquila que en el pueblo pero que en el [haciendo alusión a la finca-al pueblo] tenía la disponibilidad de recursos sobre todo alimentos para ella y su familia.

\section{Condiciones de vida actual: El apoyo}

De esta manera en su día a día inicia una lucha por la supervivencia frente a las diferentes adversidades y condiciones cotidianas, "una mujer sola a cargo de todo", manifiesta que se "dejo con su pareja cuando regre- 
so al pueblo", sin embargo pese a las diferentes situaciones la participante indica su deseo por salir adelante a partir de trabajos y de manualidades donde sus hijos se convierten en el recurso principal para luchar y buscar un mejor futuro, esto se hace evidente en el discurso de la participantes "[...] mis hijos...por ellos, todos estudiando, uno tiene dos farmacias, ellos viven aquí conmigo y tengo uno en Venezuela [...]".

En esta misma línea es fundamental resaltar como sumado a esta movilización por el bienestar de sus hijos, reconoce recursos y apoyo provenientes principalmente de la líder del barrio, de sus vecinos que también fueron víctimas del conflicto armado, de profesionales y del gobierno. Identificando en su discurso el apoyo emocional-afectivo y material recibido, indica como a partir de una red logra realizar "cursos" y a partir de allí tener una micro-empresa de cerámica "[...] al declararme en el colegio 5 de noviembre aprendí hacer sandalias, ropa interior, aprendí hacer también cosas de aseo y trabajar en el porcelanicron y tengo así una microempresa de cerámica [...]". Bajo estos presupuestos y retomando la propuesta teórica de Seligman y Csikszentmihaly (citado en Rivera-Heredia, Obregón y Cervantes, 2009) los recursos son elementos tangibles o intangibles que ayudan a manejar las diferentes situaciones de la vida y son utilizadas de manera especial para afrontar las diferentes situaciones que son percibidas como una situación problema o como generadoras de estrés.

En esta misma línea y de acuerdo con Lazarus y Folkman (1984) los recursos son las características personales que funcionan como amortiguadores de los efectos y las consecuencias del estrés, afirmando que "la forma en que un sujeto afronta una situación dependerá, en parte, de los recursos de los que disponga" (pág. 180). Desde esta mirada teórica, otro pilar que aparece como recurso psicológico para el afrontamiento de las situaciones de estrés del día a día es la sensación de fortaleza propia y la confianza en Dios, al respecto manifiesta en su discurso "[...] que me Diosito me de fuerzas, para continuar, para seguir luchando y sacar a mis hijos adelante [...]".

\section{Deseos y sueños}

Keyes $(2002,2005)$ afirma, que es necesario comprender al ser humano y a la salud mental de éste como un continuo que incluye aspectos positivos. Desde esta mirada no se excluyen aspectos negativos, ni se pretende dejar de reconocerlos, dado que hacen parte de la historia, de la vida y son los que muchas veces permiten poner en funcionamiento y movilizar todo el potencial, los recursos y las estrategias de afrontamiento que tiene la persona. Así al hacerse énfasis en los elementos positivos que le ayudan al 
individuo a seguir adelante, a tener metas en la vida y en últimas les permite sobrevivir a pesar de casi cualquier condición que enfrente. Desde esta postura teórica sin dejar de reconocer el trauma ocasionado por la violencia sociopolítica, es necesario enfrascarse en los elementos positivos que funcionan como protectores de la salud mental y física.

De manera particular en la participante sus deseos giran en torno a sus hijos -su bienestar y futuro-y el reencuentro con todos los miembros de su familia. De acuerdo con sus expresiones:

[...] cerrar los ojos, ese es mi sueño y que cada uno tenga su casa y estén bien [...]; [...] por eso nunca la felicidad es completa, hasta que no encuentre a mi familia, yo quiero encontrar aunque sea a mis hermanos yo sé que mis padres están muertos [...]: [...] ese es mi sueño poderme encontrar con mi familia, aunque acá tengo mi familia, mis hijos, pero quiero encontrar a mi familia [...].

Cabe anotar que indica a lo largo de su discurso que, aunque le gustaría regresar al pueblo para encontrar a sus familiares, aún predomina el miedo para el retorno, pues aunque ha intentado regresar en diferentes ocasiones no ha podido ingresar al pueblo, debido a que debe solicitar "un permiso" de ingreso-que tiene un costo y una ruta para acceder a el-. Es bajo estos presupuestos que menciona la necesidad de "llevar a cabo acciones concretas para la paz" "[...] que de verdad llegue la paz al pueblo... así podré ingresar mientras mis hijos me van acompañar, ahora a final de año vamos, mis hijos me van acompañar, ellos también quieren conocer quien es mi familia $[. . .]^{\prime \prime}$.

Así mismo dentro de sus sueños y deseos, indica que anhela convertirse en una "mujer emprendedora", donde pueda fortalecer y ver crecer "la microempresa de cerámica", con esto también logra brindarles mejores condiciones a sus hijos, al respecto indica "[...] luchar, hasta que Dios me recoja, hacerla más grande [...]".

Manifestándose así la confianza en un futuro, viéndolo como "algo mejor", desde esta mirada y retomando lo propuesto por Aristizábal y Palacio (2003) el sujeto que se desplaza no es un testigo sino un actor de su destino, a pesar de las circunstancias macro-sociales que lo envuelven. Así mismo afirman que a pesar de todo lo vivido, es necesario reconocer a las personas víctimas como sujeto de temores y carencias, pero también como seres con posibilidades y capacidades para valorar el riesgo y definir las estrategias para las diferentes situaciones adversas y cotidianas. 


\section{CONCLUSIONES}

A partir de la reflexión interdisciplinar y experiencial en torno a los procesos de reconstrucción de la memoria histórica de las victimas del Municipio de Arjona, incluidos sus corregimientos y veredas, mediante procesos de participación activa, sobre todo del reconocimiento a la voz, a las memorias y las condiciones que entretejen el día a día en su contextualización de la realidad del conflicto armado, se hace evidente el trauma y las huellas negativas que deja la vivencia de la violencia sociopolítica sobre la salud mental y física de la víctima. Situación que se recrudece con las condiciones de pobreza en las que se encuentran junto a sus familias producto del desplazamiento forzado. Sin embargo y sin dejar de lado el trauma ocasionado por la violencia, se reconoce a partir del discurso de la participante recursos psicológicos, sociales y familiares, estrategias de afrontamiento y elementos de bienestar que requieren ser potencializados en la implementación de estrategias de intervención psicosocial dirigidos a la promoción de la salud mental de la población víctima de violencia sociopolítica.

Cabe resaltar que el trabajo sobre la reconstrucción de la memoria es una herramienta esencial que debe tener como fin para la persona víctima de violencia sociopolítica, la dirección hacia el futuro y, de ahí, la creación de un nuevo propósito vital de otra manera se estaría asumiendo riesgos de revictimización de la población. Por esto es esencial enfocar los proyectos de intervención en torno a la integración del pasado en el presente de tal manera que se pueda facilitar la adaptación a la nueva vida, a partir del reconocimiento como "sobrevivientes", teniendo como base la voluntad y la esperanza para construir un mejor futuro para ella, sus hijos y su familia.

Para finalizar, los resultados planteados en este capítulo, pretenden aportar a las investigaciones sobre reconstrucción de la memoria en personas que han sido víctimas de violencia sociopolítica, con el fin de reconocer los recursos y estrategias de afrontamiento que deben ser potencializadas en el diseño de programas de intervención que apunten a la reconstrucción de la historia personal, con el fin de recuperar y fortalecer la identidad las víctimas, y de la esperanza en el futuro. Así y de lo propuesto por Madariaga (2002) se resalta que el objetivo primordial de la intervención y del acompañamiento psicosocial, es encaminar a que las acciones que se emprendan en pro de "reparar" a las personas, familias y comunidades definidas, propendan por transformar las condiciones que propiciaron los hechos de violencia. Resultando imperativo visibilizar la situación y el testimonio de las víctimas, con el fin de re-significar la experiencia, fortalecer la identidad 
y alcanzar la verdad, teniendo en cuenta a cada persona como sujeto histórico. Es por esto que la intervención y la atención debe ser focalizada en la promoción de la salud mental de las víctimas, sin dejar de reconocer el trauma y el impacto psicosocial generado por los crímenes de lesa humanidad en cada una de las personas. Así mismo se debe ofrecer una atención coherente a los efectos del daño causado, libre de la lógica de la guerra y de la utilización de las personas como medio para el logro de objetivos políticos e institucionales.

\section{REFERENCIAS BIBLIOGRÁFICAS}

Aristizábal, E. \& Palacio, J. (2003). Subjetivación del acto de desplazarse y aspectos psicopatológicos relacionados con experiencias violentas. Investigación y desarrollo, 11 (2), 238-253

Beristaín, C. M. (2000). Apoyo Psicosocial en catástrofes colectivas: De la prevención a la reconstrucción. Fondo Editorial Humanidades.

Bisquerra, R. (2009). Psicopedagogía de las emociones. Madrid; Editorial Síntesis.

Blanco \& Díaz (2004). Bienestar social y trauma psicosocial: una visión alternativa al trastorno de estrés postraumático. Clínica y salud. Madrid: Revista de psicología clínica y salud, 15(3), 227-252.

Breilh, J. (1997). La epidemiología entre fuegos. Taller Latinoamericano de Medicina Social. Medellín: ALAMES, 35-59.

Eisenhardt, K. M. (1989). Building theories from case study research. Academy of management review, 14(4), 532-550. Recuperado de: http://euroac.ffri.hr/ wp-content/uploads/2010/06/Eisenhardt_1989_Building-Theories-from-Case.pdf

Echeburúa, E., Corral, P. D., Amor, P. J., Zubizarreta, I., \& Sarasua, B. (1997). Escala de gravedad de síntomas del trastorno de estrés postraumático: propiedades psicométricas. Análisis y modificación de conducta, 23(90), 503-526. Recuperado de: http://zutitu.com/FitxersWeb/20/ARTICULO10.pdf

Gaborit, M. (2006). Memoria histórica: revertir la historia desde las víctimas. ECA: Estudios centroamericanos, (693), 663-684.

Gaborit, M. (2012). Reconfigurando la esperanza: prácticas sociales de la memoria en reparación, M (2012). Reflexiones urgentes en torno a la violencia sociopolítica y el malestar ético. 243-264

Keyes, C. (2002). The mental health continuum: from languishing to flourishing in life. Journal of Health and Social Behavior, 43 (2), 207-222.

Keyes, C. (2005). Mental illness and/or mental health? Investigating axioms of the complete state model of health. Journal of consulting and clinical psychology, 73(3), 539.

Lazarus, R. S., \& Folkman, S. (1984). Stress, appraisal, and coping. Springer publishing company.

Madariaga, C. (2002). Trauma psicosocial, trastorno de estrés postraumático y tortura. Disponible en www.contraste.org/textos/.../monog_psicosocial_espa- 
Aproximaciones a la violencia socio-política, memoria e identidad: Un estudio de caso en el municipio de Arjona- Bolívar

ñol.PDF.

Martín-Baró, I. (1988). La violencia política y las guerras como causas del trauma psicosocial en el Salvador. Revista de psicología del salvador. 123-141.

Martín-Baró, I. (2003). Poder, Ideología y violencia. Madrid: Trotta.

Martínez, M. (2006). La investigación cualitativa (síntesis conceptual). Revista de investigación en psicología, 9(1), 123-146.

Negrete, P. (1994). Sobre los fundamentos del pensar fragmentario. Filosofía: revista del postgrado de Filosofía de la Universidad de los Andes, (7), 65-72.

Programa Presidencial de Derechos Humanos y Derecho Internacional Humanitario. (2009). Informe de gestión 2009. Recuperado de: http://historico.derechoshumanos.gov.co/Programa/Documents/InfGestionPPDH-2009.pdf

Ramos, M., Pratts, M. F., González, M., Bernal, L., Jiménez, E. V., \& Flores, G. L. (2004). Calidad de la atención de salud. La Habana: Editorial de Ciencias Médicas.

Red Nacional de Información (RNI, 2016). Reporte General. Unidad para las víctimas.

Rivera-Heredia, M. E., Obregón Velasco, N., \& Cervantes Pacheco, E. I. (2009). Recursos psicológicos y salud: consideraciones para la intervención con migrantes y sus familias. Lira, J. Aportaciones de la Psicología a la Salud. 